\title{
O SERVIÇO SOCIAL E A CONSOLIDAÇÃO DE DIREITOS: DESAFIOS CONTEMPORÂNEOS
}

\author{
Maria Lúcia Martinelli ${ }^{1}$
}

\section{RESUMO}

O objetivo deste ensaio é trazer para a reflexão algumas questões relativas aos desafios contemporâneos que se colocam para o Serviço Social no que se refere à consolidação dos direitos sociais consagrados pela Constituição Federal de 1988 e referendados pelo projeto ético-político da profissão. Tomando por referência analítica a categoria identidade, examino os desafios que se colocam para o exercício profissional e finalizo com algumas proposições, tendo em vista a consolidação do referido projeto.

PALAVRAS-CHAVE: Serviço Social, Identidade, Direitos Sociais, Exercício Profissional.

\section{INTRODUÇÃO}

O meu olhar é nítido como um girassol [...] sinto-me nascido a cada momento Para a eterna novidade do mundo.

\section{Fernando Pessoa}

Todos nós, que nos dedicamos ao Serviço Social como área de conhecimento e de intervenção profissional, temos questões que nos mobilizam e nos convocam para a reflexão, constituindo-se em solo fecundo para nossas ações profissionais.

Para uma profissão que tem nas manifestações da questão social o seu próprio campo de ação, são muitas, evidentemente, as requisições que cotidianamente se

\footnotetext{
${ }^{1}$ Assistente Social, Doutora em Serviço Social, Docente Pesquisadora do Programa de Estudos PósGraduados em Serviço Social da PUC São Paulo e Coordenadora do Núcleo de Estudos e Pesquisa sobre Identidade. E-mail: mlmartinelli@terra.com.br.
} 
colocam para os profissionais, tanto na sua área específica de trabalho quanto no contexto social mais amplo.

Cada um de nós deve ser um atento leitor do cotidiano, deve ter um olhar nítido como um girassol para poder desvendar a conjuntura, as forças sociais aí presentes, pois para quem fez uma opção pelo social esse deciframento é indispensável.

Somos profissionais que trabalhamos entre estrutura, conjuntura e cotidiano, porém é no cotidiano que se movem as nossas ações profissionais, que o nosso trabalho profissional se realiza.

Assim, é a partir desse cotidiano fugaz, imediato, heterogêneo, como o define Agnes Heller (1972), que vamos nos construindo e reconstruindo enquanto trabalhadores sociais ${ }^{2}$.

Independentemente do nosso campo de ação, até por dever de ofício, temos de acompanhar o movimento histórico da sociedade e da profissão nesse contexto.

A nenhum de nós, assistentes sociais, devem ser estranhas as questões que se relacionam à condição humana, à vida das pessoas em sociedade, à cultura dos sujeitos, aos seus modos de viver, de lutar, de resistir, de desfrutar do lazer e, especialmente, de reivindicar direitos.

Da mesma forma, o que se passa no campo da economia, do direito, dos direitos sociais, do trabalho deve ser leitura cotidiana para cada um de nós, pois são importantes referenciais.

\footnotetext{
${ }^{2}$ Para desenvolvimento e ampliação dessa reflexão, importante consultar a obra de Heller, especialmente O cotidiano e a história (1972), pois trata-se de um clássico no que se refere à Teoria da Vida Cotidiana. Nessa obra, a filósofa húngara, nascida em Budapeste, em 1929, discípula de G. Lukács, avalia de modo rigoroso a categoria cotidiano, nível em que a reprodução social se realiza na reprodução do indivíduo enquanto tal.
} 
Podemos não atuar no campo específico da Assistência Social, mas todos estamos referidos ao contexto mais amplo das políticas públicas, o que significa dizer que não podemos estar alheios ao que se passa nesse âmbito.

Por estes motivos, entre tantos outros, é que a questão propulsora de minha atitude investigativa e ação profissional é, desde sempre, a questão da identidade.

A identidade é, por excelência, uma categoria histórica, pulsa com o tempo e com o movimento e constrói-se e reconstrói-se em meio ao jogo de forças sociais, a partir de determinações políticas, sociais, históricas, éticas e culturais ${ }^{3}$.

É uma categoria ontológica, não apenas lógica, pois expressa o modo de ser da profissão e suas formas contemporâneas de aparecer socialmente.

Parto de uma premissa analítica que situa as profissões como construções essencialmente dinâmicas, que se transformam, ao se transformarem as condições sóciohistóricas da própria sociedade, razão pela qual me reporto às formas contemporâneas de aparecer da profissão.

No caso do Serviço Social, profissão intrinsecamente vinculada à história, e que tem por matéria-prima de trabalho as múltiplas expressões da questão social, o desenvolvimento da capacidade de realizar leituras críticas e políticas da realidade é um verdadeiro imperativo, pois é a partir dessa realidade que se instituem suas demandas e requisições.

É nesse sentido que tenho afirmado sempre que a pergunta pela identidade é de natureza histórico-dialética. Sintetiza e articula dialeticamente o que somos: a forma de ser da profissão, o que fazemos: a forma pela qual a profissão aparece socialmente, ou seja, o conjunto de intervenções que realizamos em um dado momento histórico e o

\footnotetext{
${ }^{3}$ Para aprofundamento de estudos sobre tal categoria, remeto o leitor ao livro Serviço Social: identidade e alienação (2010), de minha autoria, e outras produções indicadas na bibliografia.

Revista Serviço Social \& Saúde. UNICAMP Campinas, v. X, n. 12, Dez. 2011
} 
que aspiramos fazer a partir das determinações ético-políticas de nosso projeto profissional e das requisições e demandas que emergem da realidade cotidiana.

Assim sendo, mais do que perguntar por identidade, devemos nos perguntar por identidades, por processos de identificação em curso, pois as identidades são, fundamentalmente, condição de ser e possibilidade, são permanências e transformações.

Um desafio importante, nesta perspectiva de análise, é reconhecer que a profissão, como um tipo peculiar de trabalho, como forma de especialização do trabalho coletivo, tem uma dimensão política que lhe é constitutiva e que se expressa até no menor ato de nossa vida cotidiana.

É nessa mesma perspectiva que devemos reconhecer, ainda, que a profissão tem significado sócio-histórico, recebendo impactos das transformações societárias, ao mesmo tempo em que produz, também, impactos nos processos sociais, na formulação de políticas e nos próprios padrões de intervenção profissional.

As identidades profissionais, nesse sentido, jamais poderão ser processos reiterativos, de reprodução de práticas já produzidas. Muito ao contrário, são movimento dialético, são sínteses sempre provisórias, porque históricas, de múltiplas determinações. São expressões materiais e concretas do projeto ético-político profissional, como construções que são de sujeitos coletivos, em contextos históricos determinados.

Uso a noção de sujeito coletivo pensando não só nos protagonistas institucionais da prática profissional - os assistentes sociais e os sujeitos que buscam os seus serviços - mas todos os profissionais nas diferentes formas em que realizam o seu ofício: pesquisadores, docentes, gestores, profissionais de campo, bem como os estudantes de Serviço Social. Essa concepção abrange também as organizações profissionais e as agências formadoras de ensino e pesquisa, considerando-as Revista Serviço Social \& Saúde. UNICAMP Campinas, v. X, n. 12, Dez 2011 
coletivamente, nos termos de Sader (1988), como uma "coletividade onde se elaboram identidades e se organizam práticas, através das quais seus membros pretendem defender seus interesses e expressar suas vontades, constituindo-se nessas lutas” (Ibid, p. 11).

Sujeitos coletivos expressam consciências partilhadas, são sujeitos que lutam por vontades históricas determinadas. Por isso é tão importante o conhecimento das cambiantes dinâmicas societárias, das múltiplas expressões da questão social. Tomá-la por base da requisição da profissão pela sociedade coloca a exigência da permanente interlocução com a história.

A questão social é histórica por natureza, condensa lutas sociais de sujeitos individuais e coletivos no enfrentamento das desigualdades e opressões da sociedade do capital nos vários momentos da história.

Apreender a dinâmica da vida social, os processos de produção e reprodução da vida social como determinantes da cultura, das lutas, dos enfrentamentos dos sujeitos com os quais trabalhamos é crucial para que não retiremos o seu protagonismo, ou os transformemos em vítimas.

Suas lutas cotidianas são formas de resistência, são seu modo de reivindicar direitos, são expressões de uma sociabilidade que recusa o lugar claro/escuro, de verdade e engano, que a sociedade lhe destina. São sujeitos que se instituem como tal e que se fazem presentes no cenário histórico. São bravos guerreiros, são “caçadores de si” e de sua história, são sujeitos históricos que não perdem “a estranha mania de ter fé na vida [...]”, como nos diz Milton Nascimento em "Maria, Maria”, uma de suas mais famosas canções. 
O que pensar, então, das questões da identidade profissional do Serviço Social na contemporaneidade? Em que terreno contraditório e complexo se dá a sua construção?

Na verdade, vivemos um momento de crise intensa do capital. Há uma profunda desregulamentação do mercado de trabalho, acompanhada de crescente desigualdade social, trazendo para a classe trabalhadora grandes dificuldades de acesso aos direitos sociais e aos bens socialmente produzidos.

A financeirização do capital, desvinculando-o da relação de trabalho, vem produzindo impactos substantivos sobre a classe trabalhadora, abalando seus próprios referenciais identitários.

A expansão do pensamento conservador, favorecido pelo ideário neoliberal, que se contrapõe à consolidação de princípios democráticos, estende-se por toda a sociedade, determinando a perda de padrões civilizatórios e o descaso com a vida humana.

No plano das políticas públicas e de sua operacionalização, há dificuldades de se estabelecerem princípios realmente educativos que busquem efetivar acesso e garantia de direitos para os sujeitos que são demandantes das práticas institucionais.

Enfim, o que está em jogo é um novo ciclo de profundas transformações que envolvem tanto as forças produtivas como as relações de produção.

Nesse complexo emaranhado, as próprias profissões fragilizam-se, enquanto construções coletivas, correndo o risco de perder-se em trajetos solitários.

Daí a importância do projeto contemporâneo do Serviço Social brasileiro como um norte para nossa ação profissional. Reafirmando os valores da liberdade e justiça social, já presentes no Código de 1986, o novo Código de 1993 assume a democracia como valor ético-político central, considerando-a a única organização Revista Serviço Social \& Saúde. UNICAMP Campinas, v. X, n. 12, Dez 2011 
político-social capaz de assegurar a explicitação dos valores essenciais da liberdade e da equidade. É um Código vigoroso, que fundamenta o projeto ético-político profissional, articulando-o a um projeto social mais amplo, demandando um profissional competente, crítico, qualificado teoricamente e, sobretudo com muita coragem para lutar contra os obstáculos que se interpõem em sua trajetória ${ }^{4}$.

Mais do que nunca, portanto, é oportuna a lembrança dos versos da canção “Caçador de Mim”, de Sérgio Magrão e Luiz Carlos Sá, imortalizados na voz de Milton Nascimento:

Nada a temer

Senão o correr da luta

Nada a fazer

Senão esquecer o medo [...]

Porém, sabemos que temos muito a construir ainda no que se refere à consolidação do processo democrático.

Não negamos, evidentemente, a importância dos instrumentos democráticos construídos no Brasil, a partir dos anos 1980, como conquistas dos movimentos sociais organizados e dos sujeitos políticos coletivos da sociedade civil, em seus segmentos críticos ${ }^{5}$.

A Constituição Federal de 1988 é um marco significativo desses avanços e principalmente do conjunto de instrumentos democráticos, estabelecendo uma nova concepção de Seguridade Social como política pública, não contributiva, como direito de cidadania e dever do Estado, trazendo então a Assistência Social para o campo dos direitos.

\footnotetext{
${ }^{4}$ Para sistematização e aprofundamento dos estudos sobre essa importante construção histórica, consultar Barroco (2001), citada na bibliografia.

${ }^{5}$ Importante contribuição para aprofundamento dessa análise encontra-se em Couto (2004), além da legislação brasileira referida aos instrumentos democráticos e às políticas, que também se encontra na bibliografia.
} 
Tal princípio rompe com a forma tradicional de tratar o campo da política social pública no Brasil, de modo subalterno e pouco afiançador de direitos, instituindo um novo paradigma, no qual a noção de direitos sociais ocupa lugar central como elemento fundante da relação pública entre os cidadãos e o Estado.

Na esteira das conquistas democráticas que vão se instituindo após a Constituição Federal de 1988, e que vão alargando o campo dos direitos sociais no Brasil, sem dúvida temos de mencionar o SUS (1990), o ECA (1990), a LOAS (1993), o Estatuto do Idoso (1994), a Lei de Diretrizes e Bases da Educação Nacional (1996), e mais recentemente, já nos anos 2000, a Política Nacional de Assistência, em 2004, a Norma Operacional Básica, em 2005, com vistas à implantação do Sistema Único de Assistência Social, daí a sua denominação NOB SUAS, enfim, todo um conjunto de leis regulamentadoras de cada política, num esforço concentrado de implantar um Sistema de Proteção Social no Brasil. Avançando nesta reflexão, podemos considerar que ela se expressa nos mais variados contextos, desde o Plano das Políticas Sociais Públicas ao Currículo do Curso de Serviço Social e à lei que regulamenta a profissão. Hoje temos um Sistema Nacional de Garantia de Direitos, no campo das relações sociojurídicas, abrangendo o segmento infanto-juvenil e as dinâmicas familiares, trazendo novos fundamentos para as ações nessa área.

A partir de um esforço organizativo nacional do Conselho Federal de Serviço Social, temos caminhado na construção de parâmetros para o exercício profissional em diferentes áreas ${ }^{6}$.

\footnotetext{
${ }^{6}$ Sobre essa matéria e demais referidas ao CFESS, consultar indicações na bibliografia, além de amplo material disponível no site www.cfess.org.br.
} 
Enfim, é indispensável ressaltar que nós, assistentes socais, tivemos papel destacado nessas lutas sociais e importantes transformações ocorreram em nossas identidades e práticas profissionais.

Um primeiro ponto a destacar é que hoje operamos com um novo paradigma no campo das políticas sociais públicas, no qual a noção de direitos sociais ocupa lugar central.

Pela primeira vez na história do Brasil, temos o compromisso ético-político de implantar um Sistema Único de Proteção Social, como campo de gestão unificado da Política de Assistência, numa perspectiva de intersetorialidade das políticas e de um trabalho social em rede.

Tal desenho, hoje consagrado pela Lei 12.435/2011, traz para o cenário contemporâneo uma nova forma de fazer política através dos serviços socioassistenciais, como mediação privilegiada para que indivíduos, famílias e grupos tenham a garantia de acesso a proteção social. Nosso interlocutor privilegiado deve ser o grupo familiar e não apenas a mulher, superando essa forma de conceber a política no feminino, pois frequentemente, quando se fala no PNAS, a referência é a mulher, embora no texto legal a formulação se faça em termos de matricialidade sociofamiliar.

Atuamos no plano da gestão democrática das políticas públicas, vencendo estruturas arcaicas de clientelismo e autoritarismo.

Trabalhamos na construção de lugares novos de pertencimento e socialização de crianças e jovens adultos, desde a esfera do cotidiano até as dimensões políticas de seu viver no plano do trabalho, saúde e escola.

Investimos na construção de formas novas de proteção social, de natureza preventiva e educativa, que permitam às famílias a organização e gestão de sua vida cotidiana, de modo a garantir a convivência familiar e comunitária. 
Temos também uma importante presença no fortalecimento da capacidade protetiva das famílias, através da intersetorialidade das políticas e da garantia de acesso à renda, por meio do trabalho, pois esta é a fundamental mediação humana. Nós nos tornamos humanos na relação com o outro.

Porém, o que de forma mais expressiva marca as identidades profissionais contemporâneas é a luta por direitos, é a inserção da profissão no processo de construção de uma nova ordem societária: uma sociedade justa, igualitária, livre da opressão, dominação, exploração, ou seja, uma sociedade emancipada, o que certamente não poderá ser alcançado isoladamente pelo SUAS. É indispensável a articulação com as demais políticas e a participação em processos decisórios em diferentes instâncias nacionais.

No campo específico da intervenção profissional só podemos atingir novos patamares no campo dos direitos sociais se estivermos firmemente posicionados em nosso projeto ético-político de profissão, articulando-nos a movimentos mais gerais da sociedade brasileira.

É preciso que tenhamos a necessária coragem para investir na construção de uma cultura política contra hegemônica, capaz de instituir-se como via de resistência à degradação da sociabilidade humana, imposta pelas leis de mercado e pelo capitalismo especulativo hoje vigente, que traga com sua voracidade vidas humanas de trabalhadores e seus familiares, que já não conseguem consolidar a sua identidade de trabalhador pela mediação do trabalho socialmente protegido.

É bastante procedente, neste sentido, a análise de Ricardo Antunes de que temos hoje uma nova "morfologia da classe trabalhadora" (2001), integrada pelos trabalhadores informais, precarizados e, até mesmo, desempregados, mas todos submetidos à lógica do mercado. A mercadoria de que dispõem, a sua força de trabalho, 
já não desperta mais o interesse do empregador. São homens, mulheres, jovens, adultos, anciãos, que têm sua vida consumida na árdua luta pela sobrevivência.

Muitos dos trabalhadores que integram esse segmento não são sequer alcançados pelo moderno Sistema de Proteção Social, pois vivem em condições de pobreza extrema ou em locais absolutamente inóspitos. Embora tenhamos a construção de práticas socioeducativas como horizonte ético estabelecido pelo contemporâneo projeto de profissão, na verdade estamos ainda muito frequentemente no limite de práticas que atendem meramente à manutenção da vida.

É certo que estas também são importantes e que as realizamos com o objetivo de garantir o atendimento às necessidades humanas básicas, essenciais para o existir humano.

Mas, se queremos avançar na defesa da ética e na construção de direitos, temos de realizar práticas realmente socioeducativas, ancoradas na mútua implicação entre direitos sociais, educação e cidadania, movidas pela busca de justiça, liberdade, equidade, autonomia.

Isto é um imperativo ético para todos os assistentes sociais e, de modo especial, para os trabalhadores da saúde que, como mediadores de políticas de saúde e socioassistenciais, lutam cotidianamente para garantir direitos de cidadania aos usuários das políticas que integram o campo da Seguridade Social.

É verdade que a posse de direitos por si só não libera o trabalhador das múltiplas expressões da questão social que o acometem, mas seguramente fortalecem o estatuto político de sua condição de cidadão.

Daí porque devemos estabelecer como princípio fundamental de nossas ações profissionais o reconhecimento da centralidade dos sujeitos que são demandantes e/ou usuários das políticas públicas no campo da proteção social. 
Porém, o alicerce de todo este edifício é a construção de um Estado Social, fundado na Justiça e no Direito, sem os quais a política não passa de mera ação técnica, pois tem profundamente fragilizados tanto a sua substancialidade quanto o seu caráter mediador.

É neste plano que situo a atuação do Serviço Social e sua necessária interlocução com o campo dos direitos socioassistenciais, aqueles consagrados pela Constituição Federal de 1988, a serem viabilizados pela mediação das políticas públicas.

Ao definir a Seguridade Social como Sistema de Proteção Social brasileiro, a Constituição Federal de 1988 cria as condições objetivas de romper com a forma tradicional de tratar o campo da política social pública, situando-a agora no campo de direito de cidadania e dever do Estado.

No entanto, é preciso ser cauteloso com esta análise e lembrar que a construção de direitos no âmbito da democracia é fruto de conquistas das quais participamos juntamente com os movimentos sociais organizados, dentre os quais não se pode deixar de registrar o protagonismo dos fóruns dos próprios usuários em seus movimentos sociais organizados.

São expressivas na área da saúde, por exemplo, suas conquistas no campo das doenças sexualmente transmissíveis e da AIDS, dos transplantes, dos medicamentos de alto custo, entre tantas outras. Por outro lado, é bastante significativa a profunda reflexão de Marx, em sua Crítica da Filosofia do Direito de Hegel (2010) no sentido de nos afastarmos da ilusão jurídica de pensar que onde há leis, há também justiça. O próprio cotidiano de trabalho nos mostra quantas violações e violências ocorrem na vida dos sujeitos que são demandantes e/ou usuários da Assistência pela mediação das intervenções socioinstitucionais. 
A rigor, nenhum de nós está imune a tais violações na sociedade do capital, sejamos profissionais ou usuários das políticas.

É nesta perspectiva de consolidação da justiça que se abre um fecundo caminho para nós, assistentes sociais, que estamos muito intensamente convocados para a construção de uma nova cultura política, que caminhe da institucionalidade legal para a prática efetiva dos direitos consagrados na Constituição Federal de 1988.

Consolidar nosso projeto profissional supõe investir em mediações políticas capazes de superar heranças e presenças conservadoras que alimentam gestões autoritárias e clientelistas.

É preciso olhar para o presente como doador de sentidos para o passado e como alicerce fundante de novos futuros.

Lutar por justiça e direitos e pela construção de uma efetiva presença da profissão nesse contexto exige que tenhamos compromisso político como sujeitos coletivos que partilham vontades históricas determinadas, dentre as quais é importante ressaltar:

- o fortalecimento do trabalho profissional nos espaços de construção de cidadania;

- o investimento na capacidade de fazer análises críticas, conjunturais, desvendando o jogo de forças sociais que impregnam o nosso cotidiano e as nossas ações profissionais;

- o investimento na construção de mediações capazes de refundar a política como espaço de direitos, de luta contra o grande capital;

- o investimento na construção de mediações que possibilitem refundar o social como espaço de construção de utopias e de invenção de futuros; 
- o investimento na construção de espaços sociopolíticos de consolidação do contemporâneo projeto brasileiro de profissão, dente os quais merecem destaque:

o a organização coletiva da categoria e articulação aos movimentos sociais organizados;

o a participação na gestão democrática das políticas sociais públicas;

o a qualificação da intervenção profissional nos diferentes espaços sócioocupacionais e no próprio território;

o a gestão social cotidiana dos direitos;

o o fortalecimento do processo da intersetorialidade das políticas e da construção de redes de suporte social, conforme previsto no PNAS 2004, como pilares fundamentais para a realização de uma prática profissional que assuma a sua dimensão política e a sua condição de prática educativa e de fortalecimento de vínculos familiares e sociais.

Por fim, e não menos importante, assumir o compromisso de sentir-se nascido a cada momento para a eterna novidade do mundo e inserir a profissão no processo de construção de uma nova ordem societária: uma sociedade justa, igualitária, livre de opressão, dominação e exploração, conforme disposto em nosso projeto ético-político profissional, e lutar por novas formas de acesso à renda e ao trabalho, pois esta é a principal mediação humana: nós nos fazemos humanos pela mediação do trabalho! 


\section{ABSTRACT}

The purpose of this essay is to bring some questions for reflection on the contemporary challenges posed to social work with regard to the consolidation of the social rights guaranteed by the Constitution of 1988 and endorsed by the ethical-political project of the profession. By analytical reference to the category of identity, I examine the challenges for professional practice and conclude with some propositions in order to consolidate said project.

KEYWORDS: Social Work, Identity, Social Rights, Professional Practice.

\section{REFERÊNCIAS BIBLIOGRÁFICAS}

ANTUNES, R. Os sentidos do trabalho. 4a edição. São Paulo: Boitempo, 2001.

O caracol e sua concha: ensaios sobre a nova morfologia do trabalho. São Paulo: Boitempo, 2005.

BARROCO, M.L.S. Ética e Serviço Social: fundamentos ontológicos. São Paulo: Cortez, 2001.

BRASIL. Constituição da República Federativa do Brasil. Brasília: Senado, 1988. Presidência da República. Lei $\mathbf{n}^{\mathbf{0}} \mathbf{8 . 6 6 2}$, de 7 de junho de 1993. Regulamenta a profissão de Assistente Social. . Ministério do Desenvolvimento Social e Combate à Fome. Política Nacional de Assistência Social. Brasília, 2004.

CHAUI, M. S. Brasil: mito fundador e sociedade autoritária. São Paulo: Editora Fundação Perseu Abramo, 2000.

Cidadania cultural. O direito à cultura. São Paulo: Editora Fundação Perseu Abramo, 2006. 
CONSElHo FEDERAL DE SERVIÇO SOCIAL. Código de Ética do Assistente Social. Resolução CFESS n 273, de 13 de março de 1993.

. Parâmetros para a Atuação de Assistentes Sociais na Saúde. Brasília, CFESS, 2009.

COUTO, B. R. O Direito Social e a Assistência Social na sociedade brasileira: uma equação possível? São Paulo: Cortez, 2004.

HELLER, A. O cotidiano e a história. Trad. Carlos Nelson Coutinho e Leandro Konder. Rio de Janeiro: Paz e Terra, 1972.

IAMAMOTO, M. O Serviço Social na cena contemporânea. CFESS/ABEPSS (Orgs) Serviço Social, direitos e competências profissionais. Brasília: CFESS/ABEPSS, 2009.

MARTINELLI, M.L. Serviço Social: Identidade e alienação. $14^{a}$ edição. São Paulo: Cortez, 2010.

Pensar a identidade: eis a tarefa. Um ensaio sobre a identidade profissional do Serviço Social. KARSCH, U. (Org.) Estudos do Serviço Social: Brasil e Portugal. Vol. 2. São Paulo: EDUC: 2005. Reflexões sobre o Serviço Social e o projeto ético-político profissional. Revista Emancipação, ano 6, n. 1. Ponta Grossa: UEPG, 2006. Sentido e direcionalidade da ação profissional: projeto ético-político em Serviço Social. BAPTISTA, M. V., BATTINI, O. (Orgs) A prática profissional do assistente social: teoria, ação, construção de conhecimento. Vol. I. São Paulo: Veras Editora, 2009.

MARX, K. O Capital. Crítica da economia política, 9a edição, Livro I, Volume I, Trad. Reginaldo Sant’Anna. São Paulo: Difel, 1986. 
Para a crítica econômica política. In: Manuscritos econômico-filosóficos e

outros textos. Trad. Edgar Malagodi e José Arthur Gianotti. São Paulo: Abril Cultural, 1978.

Crítica da filosofia do direito de Hegel. 1843. Trad. Rubens Enderle e Leonardo de Deus. $2^{a}$ edição revista. São Paulo: Boitempo, 2010.

MESZÁROS, I. A educação para além do capital. São Paulo: Boitempo, 2006.

NETTO, J. P. Para a crítica da vida cotidiana. In: CARVALHO, M. C. B. de, e Netto, J. P. Cotidiano: Conhecimento e crítica. 8a edição. São Paulo: Cortez, 2010.

PESSOA, F. Obra poética. Volume único. Rio de Janeiro: Companhia Aguilar Editora, 1965.

SADER, E. Quando novos personagens entraram em cena. Rio de Janeiro: Paz e Terra, 1988.

TELLES, V. S. Direitos Sociais: afinal do que se trata? 2a reimpressão. Belo Horizonte: Ed. UFMG, 2006.

YAZBEK, M. C.; MARTINELLI, M. L.; RAICHELIS, R. Fortalecendo a profissão na defesa de direitos. Serviço Social \& Sociedade, São Paulo: Cortez, ano XXIX, nº 95, 2008. 